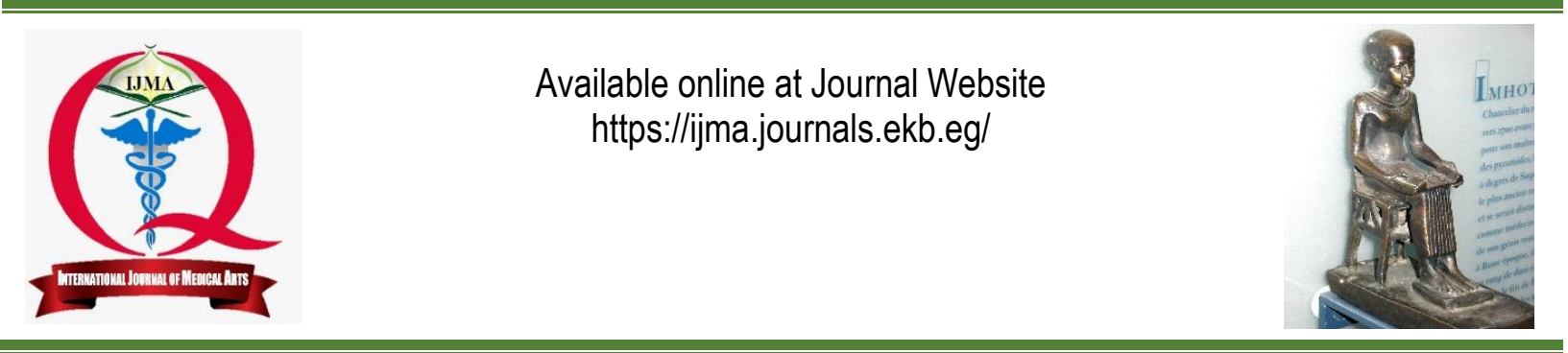

Original article

\title{
Outcome of First Trimester Pregnancy in Cases with Impending Embryonic Demise
}

\author{
Hend Maher Hassan; Mohammed Galal Nasr; Walaa Mohammed El-Bassioune
}

Department of Obstetrics and Gynecology, Damietta Faculty of Medicine, Al-Azhar University, Egypt.

Corresponding author: Hend Maher Hassan

Email: hendmaher277@domazhermedicine.edu.eg

Received at: July 24, 2019; Revised at: October 25, 2019; Accepted at: October 26, 2019; Available online at: October 26, 2019

DOI: $10.21608 / i j m a .2019 .15189 .1020$

\section{ABSTRACT}

Background: Miscarriage is the most common adverse pregnancy outcome which has detrimental psychological consequences for the woman and her partner and delays successful childbearing. Normal embryonic heart rate is about [100-200] bpm at 5 weeks gestation then it increases progressively over the subsequent 2-3 weeks. Fetal demise often occurs within one week after the slow embryonic heart rate and always occurs by the end of the first trimester.

Aim of the work: The aim of the present study was to investigate the relation between first trimester miscarriage and slow embryonic heart rate at sixth week of gestational age and other risk factors of miscarriage.

Patients and methods: A prospective observational cohort study was conducted in the department of Obstetrics and Gynecology, Al-Azhar Faculty of medicine [Damietta] during the period from September 2017 to September 2018 on 90 pregnant women who had slow embryonic heart rate [80-100] bpm at sixth week of gestational age. All were submitted to full history taking, clinical and ultrasound examination and followed up till the end of their pregnancy and outcome was documented.

Results: Percentage of aborted cases at the $8^{\text {th }}$ week of gestational age was [38.9\%], while, [20\%] at the $10^{\text {th }}$ week and [15.4\%] at $13^{\text {th }}$ week. Whom fetus had a heart rate less than 90 were at risk 23.8 times for experiencing abortions more than other females.

Conclusion: Slow embryonic heart rate is one of the earliest predictors for the first trimester fetal demise and it is one of the newest studies.

Keywords: Embryonic; Heart rate; Miscarriage; Gestational age; Pregnancy.

This is an open access article under the Creative Commons license [CC BY] [https://creativecommons.org/licenses/by/2.0/]

Please cite this article as: Hassan HM, Nasr M, El-Bassioune W. Outcome of First Trimester Pregnancy in cases with Impending Embryonic Demise. IJMA 2020; 2[1]: 173-178. 


\section{INTRODUCTION}

Heart's function is the first sign of independent fetal activity explored with non-invasive techniques such as ultrasound [U/S] [1]. Previous studies on the EHR normally measured about 100-200 beat per minute $[\mathrm{b} / \mathrm{m}]$ when it is first visible on sonography at approximately 5 weeks gestation. the rate increases progressively over the subsequent 2-3 weeks [2] . FHR $<90 \mathrm{~b} / \mathrm{m}$ at 6-8 weeks of GA has been associated with poor outcome and $<70 \mathrm{~b} / \mathrm{m}$ has been associated with pregnancy loss [3].

Fetal demise often occurs within 1 week after the slow FHR and almost always occurs by the end of the first trimester ${ }^{[4]}$. Thus, when a slow heart rate is seen at $6^{\text {th }}$ weeks, a follow-up US performed approximately 1 week later will often reveal that cardiac activity has ceased. If the embryonic heart is still beating on the follow-up US scan, the heart rate may still be slow or it may be normal. Our study was done to confirm that principle and get accurate percentage of miscarriage to those cases, also follow up cases with specific data throughout the first trimester and see if most cases are lost within 1 week or not. Also find out relation between some factors with slow EHR and miscarriage.

\section{AIM OF THE WORK}

The aim of the present study was to confirm the relation between first trimester miscarriage and slow embryonic heart rate at $6^{\text {th }}$ weeks of gestational age and other risk factors of miscarriage.

\section{PATIENTS AND METHODS}

This was a prospective observational cohort study conducted in the department of Obstetrics and Gynecology, Al-Azhar University [New Damietta] during the period from September 2017 to September 2018 on 90 pregnant women who had slow EHR [80$100] \mathrm{bpm}$ at $6^{\text {th }}$ weeks $\mathrm{GA}$.

\section{Inclusion criteria:}

18-35 years old women with $6^{\text {th }}$ weeks [confirmed by reliable regular last menstrual period; regular is defined as three consecutive cycles each 21-35 days length, average amount, no blood clots and reliable is defined by accurate date not preceding by combined oral contraception pill, breast feeding or pregnancy in the last 3 months and ultrasonographic CRL measurement [0.3-0.8] cm] normal, singleton, intra-uterine,
Spontaneous pregnancy. EHR [80-100] b/m by TVS.

\section{Exclusion criteria:}

Maternal bradycardia or any medical disorder. Non-viable fetuses. Threatened abortion. Pregnancies complicated with a vanishing twin. Medications other than folic acid supplement.

\section{Methods:}

After selection, counseling, explaining the procedure to all participants, obtaining an informed written consent to participate in the study and the local ethics committee approved this study, all participants were submitted to thorough history taking at the booking visit at $6^{\text {th }}$ weeks $\mathrm{GA}$ at which each woman was included only once.

All cases had been followed up till the end of first trimester on three visits, first one was at $8^{\text {th }}$ weeks, second one was at $10^{\text {th }}$ weeks and third one was at $13^{\text {th }}$ weeks [the end of first trimester]. In those three visits, GA was confirmed by measuring CRL. We also asked every visit including booking one about vaginal bleeding or pain at that current period. We compared between all groups as regard first trimester outcome which is "demise" if by anytime during first trimester an US scan demonstrated that cardiac activity was no longer present and "alive" if at 13.0 weeks, an ultrasound scan documented that the patient was still pregnant.

All trans-vaginally ultrasonic examinations to measure embryonic heart rate were performed by the same operator by using SonoaceR5 model 7.5MHz, [Samsung Medison co., Ltd., Seoul, Korea] ultrasound machine, patient was placed in dorsal lithotomy position, doctor on the right of her, the probe used was covered by glove and lubricant [gel] was inside and outside the glove then introduced gently into vagina. EHR was measured by M-Mode, at least ten regular cardiac cycles, the calculation of the heart rate was made by measuring the time interval of two cardiac cycles and the average values obtained from two measurements were utilized for statistical analysis. Measuring heart rate was done as follow: first, button on $\mathrm{M}$-mode was switched, arrow was put on beating chamber, sit first wave and then the successive second one, measured the distance between both waves to detect accurate fetal 
heart rate. We confirmed $6^{\text {th }}$ weeks $\mathrm{GA}$ by measuring Crown Rump Length of the fetal pole [3-8] mm which was measured from the cranial to caudal end of the body with the fetus in neutral position.

Statistics analysis: Data were analyzed with SPSS version 21. The normality of data was first tested with one-sample Kolmogorov-Smirnov test. Qualitative data were described using number and percent. Association between categorical variables was tested using Chi-square test and at different duration was tested using McNemar test. Continuous variables were presented as Mean [SD]. The two groups were compared with Student t- test while paired groups were compared by paired t-test test. Significant variables entered into Logistic regression model using Wald statistical technique to predict the most significant determinants and to control for possible interactions and confounding effects.

p-value was fixed at $5 \%$ level. The results was considered non-significant when the probability of error is more than $5 \%$ [p $>0.05]$, significant when the probability of error is less than $5 \%[p<0.05]$ and highly significant when the probability of error is less than $0.1 \%[p<0.001]$.

\section{RESULTS}

In the present study, cases enrolled at the $6^{\text {th }}$ week of GA were middle- aged females with the most are below thirty years, overweight and more than half cases had no history of miscarriage with mean fetal heart rate nearly $92 \mathrm{~b} / \mathrm{m}$ [table-1].
As regard vaginal bleeding and lower abdominal pain, all cases enrolled to this study at the $6^{\text {th }}$ week had started without both, then after two weeks at $8^{\text {th }}$ week of GA, [57.8\%] of cases had unfortunately experienced vaginal bleeding while [45.5] experienced pain, but after another two weeks [at $\left.10^{\text {th }}\right]$, percentage had hopefully decreased significantly in bleeding [40\%] but remained nearly the same in pain. Finally, at the end of the study [13 ${ }^{\text {th }}$ ] percentage also decreased significantly in pain [22.7\%] and not significant in bleeding. As regard miscarriage, [38.9\%] of cases had aborted at the $8^{\text {th }}$ week of GA and percentage decreased significantly at the $10^{\text {th }}$ week [20\%] then decreased insignificantly at $13^{\text {th }}$ week. The total percent of miscarriage was [58.9\%] [Table-2].

Percentage of aborted cases was greater than not aborted by very high significance value in all groups of FHR classifications [Table-3]

Number of cases $>30$ years who had aborted was less significantly than those were $\leq 30$ years and number of obese patients aborted was more than who did not abort but with no significant difference, meanwhile number of patients who had previous miscarriage aborted was more those did not abort with highly significant difference [Table-4].

Table [5] revealed that, previous abortion and slow heart rate were the good predictors of early pregnancy loss among studied populations.

Table [1]: Demographic and obstetric data of the studied group [ $\mathrm{n}=90$ ]

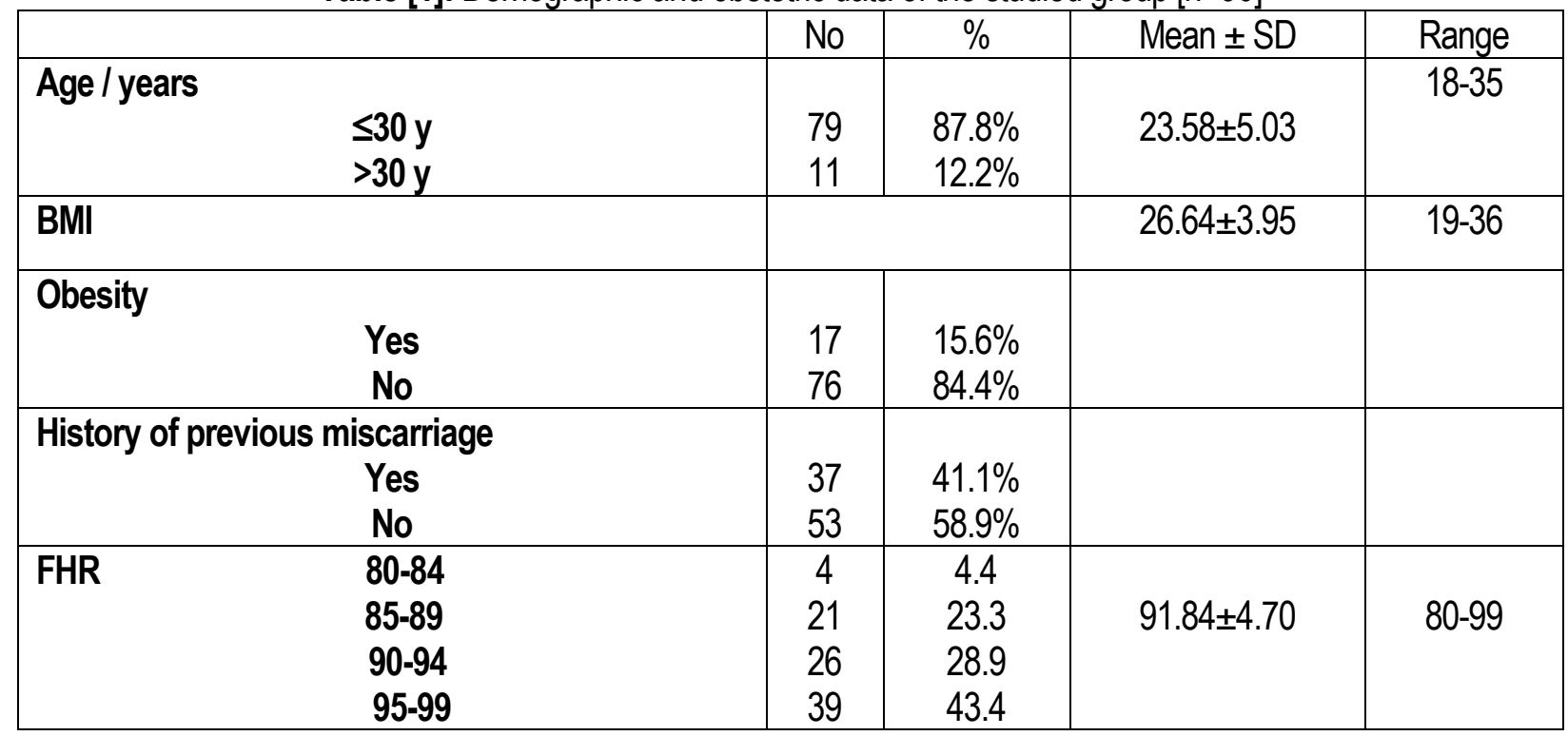


Hassan HM, et al.

Table [2]: Comparison of vaginal bleeding rate, lower abdominal pain and abortion at different follow up durations

\begin{tabular}{|c|c|c|c|c|c|}
\hline & $\begin{array}{l}8^{\text {th }} \text { week } \\
{[n=90]}\end{array}$ & $\begin{array}{c}1^{\text {th }} \text { week } \\
{[n=55]}\end{array}$ & $\begin{array}{c}13^{\text {th }} \text { week } \\
{[n=44]}\end{array}$ & total & p-value \\
\hline Bleeding & $\frac{52[57.8 \%]}{38[42 \% \%]}$ & $22[40 \%]$ & $\frac{15[34 \%]}{29[66 \%]}$ & & $\begin{array}{l}P 1=0.037^{*} \\
P 2=0.01^{*} \\
P 3=0546\end{array}$ \\
\hline Pain & 41 [45.5\%] & $25[45.6 \%]$ & $10[22.7 \%]$ & & $\begin{array}{l}\text { P1: } 0.991 \\
\text { P2: } 0.011^{*}\end{array}$ \\
\hline No & $49[54.5 \%]$ & 30 [54.4\%] & 34 [77.3\%] & & P3: $0.018^{*}$ \\
\hline Abortion & $\begin{array}{l}35[38.9 \%] \\
55[61.1 \%]\end{array}$ & $\begin{array}{l}11[20 \%] \\
44[80 \%]\end{array}$ & $\frac{7[15.9 \%]}{37[84.1 \%]}$ & $\begin{array}{l}53[58.9 \% \\
37[41.1 \%]\end{array}$ & $\begin{array}{l}\text { P1: } 0.017^{*} \\
\text { P2: } 0.007^{\star} \\
\text { P3: } 0.599\end{array}$ \\
\hline
\end{tabular}

P1: Comparison between $8^{\text {th }}$ and $10^{\text {th }}$ weeks; P2: comparison between $8^{\text {th }}$ and $13^{\text {th }}$ week; P3: comparison between $10^{\text {th }}$ and $13^{\text {th }}$ weeks.

Table [3]: Relation between abortions and fetal heart rate [FHR]

\begin{tabular}{|l|c|c|c|c|}
\hline \multirow{2}{*}{ FHR } & \multicolumn{2}{|c|}{ Study group [n=90] } & Test of significance & \multirow{2}{*}{-value } \\
\cline { 2 - 3 } & Abortions [n=53] & No abortion [n=37] & & \multirow{2}{*}{$\chi^{2}=33.19$} \\
\hline $80-84$ & $3[5.7 \%]$ & $1[2.7 \%]$ & & \\
\hline $85-89$ & $20[37.7 \%]$ & $1[2.7 \%]$ & & \\
\hline $90-94$ & $20[37.7 \%]$ & $6[16.2 \%]$ & & \\
\hline $95-99$ & $10[18.9 \%]$ & $29[78.4 \%]$ & & $<0.001^{* *}$ \\
\hline Mean \pm SD & $89.5 \pm 3.9$ & $95.16 \pm 3.629$ & $\mathrm{t}=6.89$ & \\
\hline
\end{tabular}

Table [4]: Relation between abortions and other parameters

\begin{tabular}{|c|c|c|c|c|c|}
\hline \multirow{2}{*}{\multicolumn{2}{|c|}{ Item }} & \multicolumn{2}{|c|}{ Study group $[\mathrm{n}=90]$} & \multirow[t]{2}{*}{$\chi^{2}$} & \multirow[t]{2}{*}{ p-value } \\
\hline & & Abortions [n=53] & $\begin{array}{c}\text { No abortion } \\
{[n=37]}\end{array}$ & & \\
\hline Age / years & $\begin{array}{l}\leq 30 y \\
>30 y\end{array}$ & $\begin{array}{l}43[81.1 \%] \\
10[18.9 \%]\end{array}$ & $\begin{array}{c}36[97.3 \%] \\
1[2.7 \%]\end{array}$ & 5.3 & $0.021^{*}$ \\
\hline Obesity & $\begin{array}{l}\text { Yes } \\
\text { No }\end{array}$ & $\begin{array}{l}11[20.8 \%] \\
42[79.2 \%] \\
\end{array}$ & $\begin{array}{c}3[8.1 \%] \\
34[91.9 \%]\end{array}$ & 2.65 & 0.103 \\
\hline $\begin{array}{r}\text { Previous } \mathrm{m} \\
\text { Yes } \\
\text { No }\end{array}$ & & $\begin{array}{l}31[58.5 \%] \\
22[41.5 \%]\end{array}$ & $\begin{array}{c}6[16.2 \%] \\
31[83.8 \%]\end{array}$ & 16.08 & $<0.001^{* *}$ \\
\hline
\end{tabular}

Table [5]: Logistic regression analysis of independent predictors of abortions

\begin{tabular}{|c|c|c|c|c|c|}
\hline \multirow[t]{2}{*}{ Independent predictors } & \multicolumn{3}{|c|}{ Univariate Logistic regression analysis } & \multicolumn{2}{|c|}{ Multivariate Logistic regression analysis } \\
\hline & $B$ & $\mathrm{OR}[95 \% \mathrm{Cl}]$ & p-value & $\mathrm{OR}[95 \% \mathrm{Cl}]$ & p-value \\
\hline $\begin{aligned} \text { Age / years } & \leq 30 \mathrm{y} \\
& >30 \mathrm{y}[\mathrm{r}]\end{aligned}$ & 2.12 & $\begin{array}{c}8.4 \\
{[1.02-18.6]}\end{array}$ & $0.048^{*}$ & $\begin{array}{c}1.2 \\
{[0.8-8.1]}\end{array}$ & 0.128 \\
\hline $\begin{array}{c}\text { Previous abortion } \\
\text { Yes } \\
\text { No }[r]\end{array}$ & 1.98 & $\begin{array}{c}7.28 \\
{[2.6-20.4]}\end{array}$ & $<0.001^{\star \star}$ & $\begin{array}{c}5.3 \\
{[1.39-20.5]}\end{array}$ & $0.015^{*}$ \\
\hline $\begin{array}{ll}\text { FHR } & <90 \\
& \geq 90[r]\end{array}$ & 2.59 & $\begin{array}{c}13.42 \\
{[2.9-26.6]}\end{array}$ & $0.001^{*}$ & $\begin{array}{c}23.8 \\
{[4.1-39.5]}\end{array}$ & $<0.001^{* *}$ \\
\hline
\end{tabular}




\section{DISCUSSION}

Miscarriage is the most common adverse pregnancy outcome which has detrimental psychological consequences for the woman and her partner and delays successful childbearing ${ }^{[5]}$

Previous studies showed that $\mathrm{FHR}<90 \mathrm{~b} / \mathrm{m}$ at [ $6^{\text {th }}$ $-8^{\text {th }}$ ] weeks of GA has been associated with poor outcome and $<70 \mathrm{~b} / \mathrm{m}$ has been associated with pregnancy loss ${ }^{[3,6]}$ and considered it advantageous to make the diagnosis quickly to avoid the occurrence of vaginal bleeding at an inconvenient time and place and to minimize the period of concern and uncertainty for the parents. For these reasons, a follow-up US is advisable approximately 1 week after detection of a slow early embryonic heartbeat ${ }^{[8]}$.

The aim of this study was to evaluate the outcome of first trimester pregnancy in relation to slow EHR. The mean age of studied group was [23.58], the larger percent were equal or below thirty years. More than half of the sample in this study had no history of previous miscarriage which unlike Mellerup et al.[6] study who reported that [52.5\%] of sample were at "previous one abortion".

Results of that table showed that symptoms of threatened abortion and abortion percentage decrease with advancing gestational age after first detection of slow FHR at $6^{\text {th }}$ week, and the total percent of miscarriage was [58.9] which was less than Arleo and Troiano ${ }^{[7]}$ who reported value near $80 \%$, but it was because their GA tested [ $<6.1$ weeks] was earlier and our results are comparable to Doubilet and Benson [8] [60.6\%] which worked on same GA as the present study.

The risk of miscarriage decrease by going forward in GA and the most serious period is the first two weeks after detection of slow FHR at $6^{\text {th }}$ week which can be used as an early predictor of miscarriage and that agreed with Kosus et al. ${ }^{[9]}$ who said that while evidence of abnormal embryonic heart rate [EHR] may indicate poor prognosis and higher risk of spontaneous miscarriage, routine assessment of EHR may be used as a prognostic tool for miscarriage.

As regard classification of slow FHR in our study, we made it in four groups [80-84, 85-89, 90-94, and
95-99 b/m] and studied percentage of abortion in each which were significantly more than continuation of pregnancy.

We studied association between risk factors and probability of abortion in first trimester with slow heart rate. We found that age and previous miscarriage had significant relation with abortion while obesity had not. In a research was done to study risk factors of early spontaneous abortions among Japanese, Baba et al. ${ }^{[10]}$ was in line with our results regarding obesity, as they couldn't find an association between weight status and miscarriage.

Risk of abortion in women above 30 was 8.4 folds more than below and equal to 30 years while in history of previous miscarriage was 7.2 folds. In Doubilet and Benson ${ }^{[8]}$, pregnancies with normal embryonic heart rate served as a control group which we should have had in the present study and other pregnancies were divided into two study group, slow [subdivided into slow and very slow] and the borderline embryonic heart rate but this study classified slow FHR to four groups and there were significant percentages of abortions in all of them, then it calculated risk of abortion according to FHR; high risk for miscarriage [<90] bpm was 13 folds more than moderate risk for miscarriage $[\geq 90] \mathrm{bpm}$.

These results were comparable with Doubilet and Benson [11] study, which showed that a very high rate of first-trimester demise was $[<80] \mathrm{bpm}$ at $\left[6^{0-2 t h}\right]$ weeks gestation or $[<100]$ bpm at $\left[6^{3}-7\right]$ weeks, a moderately high rate of demise was [80-89] bpm at [60-2] weeks or [100-109] bpm at [63-7] weeks, a mildly elevated rate of demise was [90-99] bpm at [60-2] weeks or [110-119] bpm at [63-7] weeks and lower demise rates was $[\geq 100] \mathrm{bpm}$ at $\left[6^{0-2}\right]$ weeks or [ $\geq 120]$ bpm at [63-7] weeks.

The most significant predictors for abortion were history of previous abortion and FHR as pregnant females with history of previous abortion were 5.3 times more at risk for abortion than other females and whom fetus had a heart rate less than 90 were at risk 23.8 times for experiencing abortions more than other females.

Conclusion: The present concluded that slow embryonic heart rate in early pregnancy could be a good predictor for the first trimester fetal 
miscarriage and the first one to start very early at $6^{\text {th }}$ week. In addition, history of previous miscarriage is a risk factor for miscarriage.

\section{REFERENCES}

1. Schmid M, Kuessel L, Klein K, Metz V, Fischer G, Krampl-Bettelheim E. First-trimester fetal heart rate in mothers with opioid addiction. Addiction 2010; 105[7]: 1265-8. [DOI: 10.1111/j.1360-0443.2010.02982.x].

2. Araujo Júnior E, Costa RS, Fonseca BC, Martins WP, Pires CR, Zanforlin Filho SM. Reference intervals of embryos/fetuses heart rate between 6 and 14 weeks of pregnancy. J Matern Fetal Neonatal Med. 2013;27[13]: 1385-8. [DOI: 10.3109/ 14767058.2013. 856416].

3. Rauch ER, Schattman GL, Christos PJ, Chicketano T, Rosenwaks Z. Embryonic heart rate as a predictor of firsttrimester pregnancy loss in infertility patients after in vitro fertilization. Fertil Steril. 2009;91[6]:2451-4. [DOI: 10.1016/j.fertnstert.2008.03.026].

4. Doubilet PM, Benson CB, Chow JS. Outcome of Pregnancies with Rapid Embryonic Heart Rates in the Early First Trimester. Am J Roentgen. 2000;175[1]:67-9. [DOI: 10.2214/ajr.175.1.1750067].

5. Feodor Nilsson S, Andersen PK, Strandberg-Larsen $\mathrm{K}$, Nybo Andersen AM. Risk factors for miscarriage from a prevention perspective: a nationwide follow-up study. BJOG 2014;121[11]:1375-85. [DOI: 10.1111/1471-0528. 12694].
6. Mellerup N, Sørensen BL, Kuriigamba GK, Rudnicki M. Management of abortion complications at a rural hospital in Uganda: a quality assessment by a partially completed criterion-based audit. BMC Womens Health. 2015;15:76. [DOI:10.1186/s12905-015-0233].

7. Arleo EK, Troiano RN. Outcome of Early First-Trimester Pregnancies [<6.1 Weeks] With Slow Embryonic Heart Rate. AJR Am J Roentgenol. 2011;197[1]:252-5. [DOI: 10.2214/ajr.10.4792].

8. Doubilet PM, Benson CB. Outcome of First-Trimester Pregnancies with Slow Embryonic Heart Rate at 6-7 Weeks Gestation and Normal Heart Rate by 8 Weeks at US. Radiology 2005;236[2]:643-6. [DOI: 10.1148/ radiol. 2362040880].

9. Kosus N, Kosus A, Turhan NÖ. First trimester volumetric measurements: relation with hormone levels and fetal heart rate. AArch Gynecol Obstet. 2012; 286[2]:365-72. [DOI: 10.1007/s00404-012-2311-9].

10. Baba S, Noda H, Nakayama M, Waguri M, Mitsuda N, Iso H. Risk factors of early spontaneous abortions among Japanese: a matched case-control study. Hum Reprod. 2011;26[2]:466-472. [DOI:10.1093/humrep/deq343].

11. Doubilet PM, Benson CB. Embryonic heart rate in the early first trimester: what rate is normal? J Ultrasound Med. 1995;14[6]:431-4. [DOI: 10.7863/jum.1995. 14.6.431]. 